\title{
A Current Review of the Children and Young People's Improving Access to Psychological Therapies (CYP IAPT) Program: Perspectives on Developing an Accessible Workforce
}

This article was published in the following Dove Press journal:

Adolescent Health, Medicine and Therapeutics

\author{
Chris Ludlow (iD) \\ Russell Hurn ${ }^{2}$ \\ Stuart Lansdell (D) \\ 'Child Wellbeing Practitioner Program \\ (CYP IAPT), Postgraduate Studies \\ Department, Anna Freud Centre, \\ London, UK; ${ }^{2}$ CYP IAPT Therapy \\ Program, Postgraduate Studies \\ Department, Anna Freud Centre, \\ London, UK
}

\begin{abstract}
The CYP IAPT program has played a leading role in workforce development in the Child and Adolescent Mental Health Service (CAMHS) in England since its inception in 2011. Despite promising evidence of CYP IAPT's benefits, significant wait times for CAHMS have convinced policy makers that a new direction for CYP IAPT is required. Since 2017, the CYP IAPT program has changed its aim from workforce development to workforce expansion, with the project aiming to train 1700 new psychological practitioners by 2021. The CYP IAPT program now consists of three training streams (a) a low-intensity workforce, (b) a schoolsbased workforce, and (c) a high-intensity workforce based on the original CYP IAPT curriculum. The purpose of this paper is to outline the three CYP IAPT workforce streams. As will be reviewed, changes to CYP IAPT have occurred within the context of emerging ideas from dissemination science and government reviews that outline the shortcomings of traditional service models. Consequently, CYP IAPT practitioners are now increasingly being trained in the delivery of novel psychological interventions to address some of these shortcomings. A range of low-intensity interventions are being deployed by CYP IAPT practitioners to target mild-tomoderate anxiety, depression, and conduct. A recent meta-analysis indicates that low-intensity psychological interventions show promise for children and adolescents in efficacy trials. Nevertheless, further research is required to understand its effectiveness in real-world settings and to see if treatment effects are sustained over time. As such, this paper recommends that CYP IAPT services evaluate the long-term effectiveness of low-intensity work and subject their methods and findings to peer review.
\end{abstract}

Keywords: psychological therapies, dissemination, mental health disorders, child/ adolescent, guided self-help, cognitive behavior therapy

\section{Introduction}

The Children and Young People's Improving Access to Psychological Therapies Programme (CYP IAPT) has played a key role in improving the provision of care for children and adolescents in England since its inception in 2011. ${ }^{1}$ Between 2011-2016, the CYP IAPT programme offered workforce development for staff working in Child and Adolescent Mental Health Services (CAMHS), local authorities, and nongovernment organisations across England. During this period, the CYP IAPT programme trained over 1000 therapists in evidence-based psychological therapies and 207 managers and supervisors in evidence-based service delivery models. ${ }^{2}$ The
Correspondence: Chris Ludlow Child Wellbeing Practitioner Program (CYP IAPT), Anna Freud Centre, The Kantor Centre of Excellence, 4-8 Rodney Street, London NI 9JH, UK

Tel +442077942313

Email c.ludlow@ucl.ac.uk 
principal aim of the CYP IAPT programme was "service transformation". The rationale was that services would be transformed by training practitioners in routine outcome monitoring, service user participation, and evidence-based psychological therapies. The CYP IAPT service transformation initiative also offered National Health Service (NHS) clinicians access to evidence-based training through e-learning and outreach consultation. ${ }^{1}$

Despite promising evidence of CYP IAPT's benefits, ${ }^{3}$ rising demand for services convinced policy makers that a new direction for CYP IAPT was required to alleviate pressure on specialist CAMHS., ${ }^{4,5}$ As such, the Department of Health modified the remit of CYP IAPT so that its aim would be to train and expand the CAMHS workforce. ${ }^{4}$ The Department of Health concluded that traditional training pathways (eg, clinical psychology, family therapy, child psychotherapy) were failing to meet the demands being placed on the NHS, ${ }^{6}$ and that a "lowintensity" workforce was required to provide prevention and treatment for children and adolescents with common mental health problems. ${ }^{7}$ A new low-intensity workforce might help to reduce wait times and free specialist clinicians (eg, clinical psychologists) to work with more complex cases - a service delivery model known as "task shifting" in the health dissemination literature. ${ }^{8,9}$

In 2017, a new workforce initiative came into effect with around 210 trainees across the country starting an innovative CYP IAPT curriculum based on Guided SelfHelp (GSH) principles. In 2018-2019, the program continued to expand with approximately 630 trainees commencing at multiple training sites across England. Furthermore, a new pilot started in 2019 with a smaller number of trainees placed in schools, which is a part of a government plan to increase mental health support in schools and colleges. ${ }^{6}$ Overall, these changes represent large investments of public money in CAMHS and have been described by the Department of Health as "transformational". ${ }^{10}$ Another significant aspect of these changes is that it will bring CYP IAPT more in line with the adult IAPT service (see Clark et $\mathrm{al}^{11}$ for a review), a program that has been described as the largest centralised psychological therapies initiative in the world. ${ }^{12}$ Currently, there are no published articles in the peer review literature describing recent changes to the CYP IAPT program. As such, the purpose of the present article is to describe the new CYP IAPT workforce, outline the curriculum, and discuss the challenges facing CYP IAPT as it attempts to expand the CAMHS workforce.

\section{The CYP IAPT Workforce}

A number of factors have played a role in the expansion of the CYP IAPT workforce. For example, advances in implementation science have made it possible to explore new models of service delivery that increase the scalability and accessibility of psychological therapies (eg, digital therapies, the use of paraprofessionals, task shifting; see Kazdin et al ${ }^{9}$ for a review). Additionally, current policy developments including a government Green Paper $^{6}$ - recommend reduced wait times for specialist CAMHS and the provision of care in non-clinical settings (eg, schools). The government has described its new plan to provide support in schools as "ambitious". ${ }^{10}$ Over the long term, there is an aim to increase the CAMHS and schools-based workforce by up to 8000 new staff. ${ }^{10}$ To put this into context, this is comparable in scale to the current NHS CAMHS workforce, which is comprised of around 7000 full-time equivalent professionals. It is anticipated that CYP IAPT will play a significant role in the training of these new workers.

In this section, dissemination models and government policies will be explored to further elucidate the rationale for recent developments in the CYP IAPT program. The discussion will end with a description of the new CYP IAPT workforce streams. The workforce streams include (a) a low-intensity workforce, (b) a schools-based workforce, and (c) a high-intensity workforce. These workforce streams aim to meet the demands of policy makers and will significantly reorganize CAMHS provision in England once fully implemented. These changes are part of a wider suite of NHS reforms that aim to reduce wait times for specialist CAMHS down to four weeks. ${ }^{6}$

\section{Service Delivery Models}

Commentators $^{13-15}$ argue that innovative solutions are required to solve the complex problems facing CAMHS services worldwide. There is emerging evidence that access to youth mental health may be increased by offering treatment outside of traditional healthcare environments, ${ }^{16}$ with some young people perceiving non-clinical environments as less stigmatizing. ${ }^{17,18}$ Treatment outcomes delivered in schools, ${ }^{19}$ primary care, ${ }^{20}$ or through the internet ${ }^{21}$ are often equivalent to outcomes delivered by traditional mental health services, especially for mild-to-moderate problems. Many CAMHS services across England prioritize severe and complex cases, which means children with mild-to-moderate problems often experience significant wait times. ${ }^{6}$ The key problem with this approach is that 
psychiatric symptoms tend to persist or escalate with time for a significant minority of children. ${ }^{22-24}$ For example, in one longitudinal study using a general population sample, ${ }^{23}$ over $50 \%$ of children who experienced clinical symptoms at baseline also scored in this range when assessed 12 months later. As such, timely treatment delivered to all cases across the severity spectrum could be conceptualized as preventative. To illustrate, one study showed that anxious children who responded to CBT during childhood were less vulnerable to drug misuse as young adults. ${ }^{25}$

In light of this evidence, some authors ${ }^{26,27}$ argue that the solution lies in developing new models of care that help patients receive an appropriate dose of psychological therapy in a timely manner. For example, the Thrive Framework recommends basing treatment decisions on clinical need rather than severity level or diagnosis. ${ }^{28}$ Likewise, stepped care models demonstrate economic benefits in CAMHS settings $^{29-31}$ and are supported by the World Health Organization (WHO) ${ }^{32}$ and the National Institute of Health Care Excellence (NICE). ${ }^{33}$ Although stepped care has been successfully implemented in adult IAPT services, ${ }^{34}$ such initiatives have had limited implementation in CAMHS, despite there being emerging evidence for the effectiveness of low-intensity treatments when delivered within a stepped care framework for youth. ${ }^{35}$

\section{Government Reviews}

A number of important government reviews have informed mental health policy and funding in England over the past four years. ${ }^{4,6,36}$ The Mental Health Taskforce to the NHS in England set out an ambitious service transformation plan for CAMHS in the Five Year Forward View of Mental Health, ${ }^{5}$ which led to funding being made available to train 1700 lowintensity CYP IAPT therapists. ${ }^{7,37}$ Furthermore, a recent government Green Paper by the Departments of Health and Education, Transforming Children and Young People's Mental Health Provision, ${ }^{6}$ recommended plans and funding for a schools-based mental health workforce, with rollout to reach 20,000 schools and colleges by 2023 .

The Green Paper commissioned a systematic review of the evidence to see "what works" within child and adolescent mental health. Although the review identified a number of evidence-based principles, one conclusion has important implications for workforce development. The systematic review concluded that therapists do not always require intensive professional training to be effective with mild-tomoderate conditions. That is, the review states that treatment can be delivered by "trained nonclinical staff with adequate supervision"6 as they have comparable outcomes to professional therapists. Although the authors are yet to subject their methodology to peer review, similar findings have been reported elsewhere in the literature. ${ }^{38}$

Given these points, an evidence-informed servicedelivery model for CAMHS might include: (a) providing timely treatment across the severity spectrum, (b) increasing access to treatment in non-clinical settings, (c) using a stepped care approach, and (d) developing a diverse professional workforce mix that consists of low-intensity workers and traditionally trained therapists.

\section{The New Direction in CYP IAPT Training}

Taken together, these ideas support a new direction for service provision in CAMHS and CYP IAPT. Changes to the CYP IAPT training framework started in 2017 with the introduction of a low-intensity workforce stream, and continued in 2019 with the addition of a school-based workforce stream. These changes were informed by the principles, policies, and objectives reviewed above. ${ }^{8,37}$ The three training streams aim to address prevention, work in schools, and specialist care. At the time of publication, the CYP IAPT training streams were as follows:

(a) a community-based workforce that delivers lowintensity psychological interventions for common mental health problems (ie, mild-to-moderate anxiety, depression, and conduct) in CAMHS, local authorities, and third-sector organizations - known as Child Wellbeing Practitioners (CWPs);

(b) a schools-based workforce that delivers the same interventions delivered by the CWPs, but within an educational setting - known as Educational Mental Health Practitioners (EMHPs); and

(c) a high-intensity workforce based on the original CYP IAPT training model (see Shafran et al ${ }^{1}$ for a review) targeted to expand the specialist workforce (ie, CBT, systemic practice, parent training, counselling interventions for ages $0-5$, counselling interventions for autism spectrum disorder and learning disabilities, and interpersonal psychotherapy) ${ }^{37}$ - known as the CYP IAPT Therapy Course/Recruit-to-Train Program.

As an overview, Table 1 shows the relationship between referral problems, treatments, and the CYP IAPT workforce that supports various patient populations. 
Table I Psychological Problems, Treatments, and Relevant CYP IAPT Workforce

\begin{tabular}{|l|l|l|}
\hline Presenting Problem & Treatments & Workforce \\
\hline $\begin{array}{l}\text { Mild-to-moderate } \\
\text { depression, anxiety, } \\
\text { and conduct }\end{array}$ & $\begin{array}{l}\text { Low-intensity } \\
\text { treatments }\end{array}$ & CWP \& EMHP \\
\hline $\begin{array}{l}\text { Mild-to-severe } \\
\text { depression, anxiety, } \\
\text { trauma, and conduct }\end{array}$ & $\begin{array}{l}\text { High-intensity CBT, } \\
\text { IPT-A, and behavioral } \\
\text { parent training }\end{array}$ & $\begin{array}{l}\text { High-intensity } \\
\text { CYP IAPT/ } \\
\text { recruit-to-train }\end{array}$ \\
\hline $\begin{array}{l}\text { ASD with co-occurring } \\
\text { depression, anxiety, } \\
\text { and conduct }\end{array}$ & $\begin{array}{l}\text { CBT, behavior therapy, } \\
\text { \& ASD-specific } \\
\text { interventions }\end{array}$ & $\begin{array}{l}\text { High-intensity } \\
\text { CYP IAPT/ } \\
\text { recruit-to-train }\end{array}$ \\
\hline $\begin{array}{l}\text { Behavioral and } \\
\text { emotional problems } \\
\text { for 0-5s }\end{array}$ & $\begin{array}{l}\text { Behavioral parent } \\
\text { training \& VIG }\end{array}$ & $\begin{array}{l}\text { High-intensity } \\
\text { CYP IAPT/ } \\
\text { recruit-to-train }\end{array}$ \\
\hline
\end{tabular}

Abbreviations: CWP, Child Wellbeing Practitioner; EMHP, Educational Mental Health Practitioner; CBT, Cognitive Behavior Therapy; IPT-A, Interpersonal Psychotherapy for Adolescents; ASD, Autism Spectrum Disorder; VIG, Video Interaction Guidance.

\section{CYP IAPT Curriculum: Overview and Objectives}

This section gives an overview of the "new workforce" curriculum (ie, CWP and EMHP curricular collectively). Specifically, this section will review the CWP and EMHP curricula by examining (a) interventions taught on the program, (b) the length and nature of the training, and (c) evidence-based principles common to all CYP IAPT trainings. This review will hopefully help readers understand the skillset of these new workers and the scope and limits of their practice. Finally, the high-intensity CYP IAPT curriculum will not be reviewed in this paper. It remains largely unchanged since its inception in 2011. As such, interested readers can find a number of excellent reviews summarizing this curriculum elsewhere (eg, Fonagy et $\mathrm{al}^{39}$ and Shafran et $\mathrm{al}^{1}$ ).

A recent UK mental health survey estimated that $12.8 \%$ of 5-19 year olds met clinical threshold for a diagnosable mental health disorder in $2017 .{ }^{40}$ The survey estimated that $33.6 \%$ of these children received no professional help for their difficulties. Improving access to treatment has been a key objective of CYP IAPT since its establishment. ${ }^{4}$ Nevertheless, if prevalence surveys are correct, increasing access will require a significant expansion of the mental health workforce. One proposed solution to scaling-up psychological interventions is to develop a mixed workforce of professionals. ${ }^{41}$ That is, a workforce that consists of traditional professionals (eg, clinical psychologists, child psychotherapists, family therapists) supported by a workforce of practitioners that deliver low-intensity interventions. The CWPs and the more recently established EMHPs were introduced to fulfill this aim.

Innovative workforce models are required to meet the challenges and demands facing CAMHS and the NHS. The Mental Health Workforce Plan for England ${ }^{7}$ identified the adult IAPT service as an example of such a model. Adult IAPT workers are trained and closely supervised for 12 months in the delivery of low-intensity psychological interventions. Despite shorter training than conventional therapists, studies indicate that IAPT workers achieve comparable recovery rates ${ }^{34,42,43}$ to professionally trained therapists. ${ }^{44}$ The CWP and the EMHP training models have been built on the success of the adult IAPT program. The CWP curriculum was developed in 2017 by the CWP Expert Curriculum Group chaired by the National Clinical Adviser for Child and Young People's Mental Health for NHS England - Peter Fonagy (P. Fonagy, email communication, June 2019). The EMHP curriculum adopted the CWP curriculum in 2019, but EMHPs also receive additional training on working within an educational context.

The new workforce curriculum trains practitioners in the delivery of low-intensity interventions for low-tomoderate mental health problems. The primary intervention philosophy adopted by the curriculum is based on guided self-help (GSH) principles. In GSH, a practitioner helps patients manage mental health problems by recommending self-help strategies. To illustrate, a prototypical GSH intervention for child anxiety disorders consists of (a) a self-help manual that assists parents to develop an exposure hierarchy, (b) four $1 \mathrm{hr}$ face-to-face sessions with a therapist and (c) four 20 mins telephone sessions. ${ }^{45}$ The role of the practitioner is to encourage the parent to work through the manual, practice skills, and problem solve intervention barriers. A randomized controlled trial (RCT) showed that parent-led GSH achieved a 50\% recovery rate for child anxiety disorders, compared with a $25 \%$ recovery rate in the waitlist control group. ${ }^{45}$

Similar RCTs have been conducted examining the benefits of GSH for low mood, adolescent anxiety, and childhood conduct. Overall, GSH benefits some children and adolescents, especially when problems are mild or moderate. For example, a recent meta-analysis by Bennett et $\mathrm{al}^{46}$ showed that GSH is a promising treatment for mental health problems in children and adolescents. Effect sizes for GSH were in a medium-to-large range for anxiety (Hedges' $g$ 0.64, 95 CI 0.38-0.90), behavior (Hedges' $g$ 0.44, CI 0.28-0.60), and depression (Hedges' $g=0.47,95$ CI $0.21-0.72$ ) when 
compared with a control group (ie, waiting list, attention, nonactive, and treatment-as-usual). Nevertheless, despite these promising findings, the meta-analysis showed that GSH is less effective than traditional therapies such as CBT.

Although more research is required to further establish the evidence base for GSH within pediatric populations, the justification for adopting GSH in CYP IAPT is based on a broader range of considerations, such as ease of implementation, cost-effectiveness, and straightforward therapist training. ${ }^{8}$ To illustrate, the adult IAPT program has shown that GSH can be rolled out and upscaled quickly. Over a 11-year period, IAPT has grown to service around 960,000 people per year. Around $48 \%$ of treatment episodes in the adult IAPT program are lowintensity cases (eg, guided self-help, computer-based CBT) ${ }^{11}$ with $36 \%$ of the IAPT workforce classed as "lowintensity workers". ${ }^{47}$ The adult IAPT program has demonstrated that GSH practitioners can be effectively trained within a short timeframe (ie, 12 months) - with around 2520 low-intensity workers qualifying in the program's first seven years. ${ }^{47}$ Although the low-intensity approach has increased access for adults, there has been limited dissemination of the GSH approach within CAMHS settings. This is despite the fact that child and adolescent studies show that GSH is more cost-effective than traditional therapies, ${ }^{30,31}$ and GSH options do not seem to compromise recovery for children and adolescents - especially when delivered within a stepped care framework. $^{35}$

\section{Training Model for Child Wellbeing Practitioners and Educational Mental Health Practitioners}

The CWP and EMHP trainees enroll in a postgraduate qualification for 12 months at a higher education institute and are employed by a participating NHS CAMHS, local authority, or third sector organization. During their education and placement, practitioners are trained to deliver the following interventions for children and adolescents aged between $6-18$ years:

(a) parent-led GSH for primary-school-aged children with mild-to-moderate anxiety disorders; ${ }^{45}$

(b) guided self-help for mild-to-moderate adolescent depression, based on behavior activation principles; ${ }^{48}$

(c) guided self-help for mild-to-moderate adolescent anxiety disorders, based on CBT principles; and (d) parent-led GSH for mild-to-moderate behavior problems (primary-school-aged), based on social learning theory. ${ }^{49}$

Services are responsible for screening cases and providing onsite clinical supervision. The CWPs and EMHPS are not trained in the treatment of posttraumatic stress disorder, obsessive compulsive disorder, nor severe and complex mental health presentations. Severe and complex cases are seen by existing CAMHS professionals (eg, clinical psychologists, family therapists) or high-intensity CYP IAPT therapists. All CYP IAPT trainings - including the CWP and EMHP programs - incorporate the following common elements: (a) didactic lectures on clinical interventions (b) weekly onsite clinical supervision (c) videotaping trainee performance, and (d) mandatory use of routine outcome monitoring (ROM) feedback. ${ }^{1}$ Mandatory ROM measures include the Revised Child Anxiety and Depression Scale (RCADS) ${ }^{50}$ the Strengths and Difficulties Questionnaire (SDQ), ${ }^{51}$ and the Goal-Based Outcomes (GBO) scale. ${ }^{52}$ Furthermore, all CYP IAPT training programs place a strong emphasis on evidence-based practice within the context of service user involvement, shared decision making, ${ }^{53}$ and goal-based work. ${ }^{54}$

Lastly, although CWP and EMHP services are generally limited to 8 sessions of treatment, a key feature of these services is not the number of sessions per se, but the principle that intervention should be brief and time-limited.

\section{Future Challenges}

We have outlined the current state of the CYP IAPT program and summarized the theoretical ideas informing its development. Government policies and NHS commitments indicate that the CYP IAPT program has a positive future with ongoing funding allocated to continue its expansion. Furthermore, implementation science principles support the increased deployment of the CYP IAPT approach, such as stepped care, routine outcome monitoring, and task shifting. The CYP IAPT program, however, is not without its critics. The program has been criticized for focusing too much on cognitive behavioral therapies and short-term treatments. ${ }^{55}$ Furthermore, there is growing awareness that the adult version of the IAPT program has shortcomings. Cited problems in the adult program include low recovery rates, ${ }^{56}$ treatment models failing to take contextual factors into account, ${ }^{57}$ and high therapist burnout. ${ }^{58}$ Because CYP IAPT is being expanded, there needs to be greater scrutiny of the CYP IAPT model to make sure mistakes made in the 
adult program are not repeated in the child and adolescent sector.

One concern facing the future of CYP IAPT is the effectiveness of its treatments. Several low-intensity therapies currently used in CYP IAPT are modifications of adult treatments, and have not been thoroughly tested in child and adolescent populations. Despite emerging evidence supporting the short-term efficacy of GSH as a treatment option for children and adolescents, more needs to be understood about its long-term efficacy and its effectiveness outside research trials. As reviewed above, GSH is effective when compared to a no-treatment control group, but it is not as effective as face-to-face CBT. Furthermore, the long-term effectiveness (ie, $>12$ months post treatment) of GSH compared to standard treatment is currently unknown. ${ }^{59}$ Research findings and clinical opinion are rapidly evolving in this area. To illustrate, the 2005 NICE guideline for depression in children and young people recommended GSH for mild depression. ${ }^{60}$ Nevertheless, the most recent (June 2019) NICE guideline ${ }^{33}$ for depression does not recommend GSH because NICE concluded that treatment effects are not sustained over time. As an alternative, NICE recommends digital CBT for mild depression in children and adolescents. It is possible that CWPs and EMHPs will receive training on Digital $\mathrm{CBT}$ in the future so that the curriculum remains NICE compliant. Nevertheless, this example illustrates how best practice in this field is still developing and evolving.

Given the fact that the evidence base in this field is still emerging, it is imperative that a robust evaluation of the CWP and EMHP programs is implemented. Evaluations of the CWP program are currently underway with sites collecting session-by-session treatment data. Additionally, the government Green Paper states that the EMHP program and its associated school-based teams (ie, Mental Health Support Teams) will be "robustly evaluated". ${ }^{6}$ Nevertheless, despite these aspirations, it should not be taken as a given that these aims will be realized. The CAMHS sector in England has a poor track record of collecting outcomes data. For example, a recent evaluation by the Child Outcome Research Consortium (CORC) experienced significant difficulties evaluating routine practice in CAMHS due to low compliance with data collection. In the CORC evaluation, only $25 \%$ of closed CAMHS cases had paired (ie, pre and post treatment measures) child-report data. ${ }^{2}$ The CWP and the EMHP programs could look to the adult IAPT program for guidance on how to conduct a high-quality service evaluation. The adult IAPT program obtains complete clinical data for around
$98.5 \%$ of cases. ${ }^{11,61}$ Importantly, missing data in the adult IAPT program is treated in a similar manner to a research trial. That is, cases without post-treatment scores are assigned a "non-recovered" status. Running a statistical analysis on an incomplete dataset runs the risk of biased results and invalid conclusions. ${ }^{62}$ If such a conservative strategy were taken in the CORC evaluation of CAMHS, $75 \%$ of cases would have been automatically assigned a "non-recovered" status.

The CWP and EMHP programs are in a pilot phase at this stage. Lessons learnt from the CORC evaluation and adult IAPT should be taken on board when evaluating the new workforce initiative so that its impact on child mental health can be accurately assessed over the coming years. Initial signs suggest positive indicators from the first two years of the CWP pilot, but we await with anticipation for the national data to be published. Anecdotal feedback suggests that sites (eg, London and the South East; South West England) using software-assisted ROM systems have more complete datasets than sites relying on manual entry. As such, we recommend that all CWP and EMHP sites implement technology-assisted ROM systems, and that services evaluate the long-term effectiveness of low-intensity work and subject their methods and findings to peer review.

\section{Conclusion}

Innovative solutions are required to improve access and reduce wait times for children and adolescents requiring mental health support in England. The CYP IAPT program is attempting to achieve these aims by increasing the size of the CAMHS workforce, offering low-intensity treatments, and providing support in schools. The CWPs and EMHPs are part of a new workforce that deliver low-intensity interventions for anxiety, depression, and conduct. The CWP and EMHP treatment philosophy is based on GSH; however, the programs also incorporate CYP IAPT principles such as goal-based work, routine outcome monitoring, and shared decision making. Although there is evidence supporting the use of GSH in clinical practice with children and adolescents, there are still questions about its long-term effectiveness and the types of patients it is best suited to help. As such, it is imperative that the new workforce program is effectively evaluated. The adult IAPT program's service evaluation model represents best practice in the field. The CYP IAPT program should embrace lessons learnt from past unsuccessful CAMHS evaluations and adopt best-practice service evaluation models to ensure the current "transformative" changes are truly effective in improving the lives of children and young people. 


\section{Disclosure}

Chris Ludlow, Russell Hurn, and Stuart Lansdell work on CYP IAPT programs at the Anna Freud Centre/University College London and report no other conflicts of interest in this work.

\section{References}

1. Shafran R, Fonagy P, Pugh K, Myles P. Transformation of mental health services for children and young people in England. In: Beidas RS, Kendall PC, editors. Dissemination and Implementation of Evidence-Based Practices in Child and Adolescent Mental Health. Oxford, UK: Oxford University Press; 2014:158-178.

2. Wolpert M, Jacob J, Napoleone E, Whale A, Calderon A, EdbrookeChilds J. Child-and Parent-Reported Outcomes and Experience from Child and Young People's Mental Health Services 2011-2015. London, UK: CAMHS Press; 2016.

3. Edbrooke-Childs J, Calderon A, Wolpert M, Fonagy P. Children and Young People's Improving Access to Psychological Therapies: Rapid Internal Audit. London, UK: Evidence-Based Practice Unit, Anna Freud Centre; 2015.

4. Department of Health. Future in Mind: Promoting, Protecting and Improving Our Children and Young People's Mental Health and Wellbeing. London, UK: NHS England Publication; 2015.

5. Mental Health Taskforce. The Five Year Forward View for Mental Health. London, UK: Department of Health and Social Care; 2016.

6. Department of Health and Social Care and Department for Education. Transforming Children and Young People's Mental Health Provision: A Green Paper. London, UK: Crown Copyright; 2017. doi:9791-5286-0061-3

7. NHS England. Mental Health Workforce Plan for England. London, UK: Health Education England; 2017.

8. Fonagy P. Priorities in children and young peoples' mental health: economic and scientific considerations. Presentation at: Child Wellbeing Practitioner Shared Learning Event; London, UK: Anna Freud National Centre for Children and Families; 2019 April 26.

9. Kazdin AE, Rabbitt SM. Novel models for delivering mental health services and reducing the burdens of mental illness. Clin Psychol Sci. 2013;1(2):170-191. doi:10.1177/2167702612463566

10. Department of Health and Social Care and Department for Education. Government Response to the First Joint Report of the Education and Health and Social Care Committees of Session 2017-19 on Transforming Children and Young People's Mental Health Provision: A Green Paper. London, UK: House of Commons; 2018.

11. Clark DM. Realizing the mass public benefit of evidence-based psychological therapies: the IAPT program. Annu Rev Clin Psychol. 2018;7(14):159-183. doi:10.1146/annurev-clinpsy-050817-084833

12. McHugh RK, Barlow DH. The dissemination and implementation of evidence-based psychological treatments: a review of current efforts. Am Psychol. 2010;65(2):73. doi:10.1037/a0018121

13. McGorry P, Bates T, Birchwood M. Designing youth mental health services for the 21st century: examples from Australia, Ireland and the UK. Br J Psychiatry. 2013;202(Suppl):30-35. doi:10.1192/bjp. bp. 112.119214

14. Cotgrove A. The future of crisis mental health services for children and young people. Child Adolesc Ment Health. 2018;23(1):1-3. doi:10.1111/camh.12259

15. Wolpert M. Rethinking public mental health: learning from obesity. Lancet Psychiatry. 2018;5(6):458-460. doi:10.1016/S2215-0366(18) 30046-4

16. Patulny R, Muir K, Powell A, Flaxman S, Oprea I. Are we reaching them yet? Service access patterns among attendees at the headspace youth mental health initiative. Child Adolesc Ment Health. 2013;18 (2):95-102. doi:10.1111/j.1475-3588.2012.00662.x
17. Bowers H, Manion I, Papadopoulos D, Gauvreau E. Stigma in school-based mental health: perceptions of young people and service providers. Child Adolesc Ment Health. 2013;18(3):165-170. doi:10.1111/j.1475-3588.2012.00673.x

18. Fazel M, Garcia J, Stein A. The right location? Experiences of refugee adolescents seen by school-based mental health services. Clin Child Psychol Psychiatry. 2016;21(3):368-380. doi:10.1177/ 1359104516631606

19. Mychailyszyn MP, Brodman DM, Read KL, Kendall PC. Cognitivebehavioral school-based interventions for anxious and depressed youth: a meta-analysis of outcomes. Clin Psychol Sci Pract. 2012;19(2):129-153. doi:10.1111/j.1468-2850.2012.01279.x

20. Richardson LP, Ludman E, McCauley E, et al. Collaborative care for adolescents with depression in primary care: a randomized clinical trial. JAMA. 2014;312(8):809-816. doi:10.1001/jama.2014.9259

21. Vigerland S, Lenhard F, Bonnert M, et al. Internet-delivered cognitive behavior therapy for children and adolescents: a systematic review and meta-analysis. Clin Psychol Rev. 2016;50:1-10. doi:10.1016/j. cpr.2016.09.005

22. Weems CF, Hayward C, Killen J, Taylor CB. A longitudinal investigation of anxiety sensitivity in adolescence. J Abnorm Psychol. 2002;111(3):471. doi:10.1037/0021-843X.111.3.471

23. Leikanger E, Larsson B. One-year stability, change and incidence in anxiety symptoms among early adolescents in the general population. Eur Child Adolesc Psychiatry. 2012;21(9):493-501. doi:10.1007/ s00787-012-0284-7

24. Voltas N, Hernández-Martínez C, Arija V, Canals J. The natural course of anxiety symptoms in early adolescence: factors related to persistence. Anxiety Stress Coping. 2017;30(6):671-686. doi:10.108 0/10615806.2017.1347642

25. Kendall PC, Safford S, Flannery-Schroeder E, Webb A. Child anxiety treatment: outcomes in adolescence and impact on substance use and depression at 7.4-year follow-up. J Consult Clin Psychol. 2004;72 (2):276. doi:10.1037/0022-006X.72.2.276

26. York A, Kingsbury S. CAPA: The Choice and Partnership Approach: A Service Transformation Model. London, UK: CAPA Systems; 2013.

27. Neufeld SAS, Jones PB, Goodyer IM. Child and adolescent mental health services: longitudinal data sheds light on current policy for psychological interventions in the community. J Public Ment Health. 2017;16(3):96-99. doi:10.1108/JPMH-03-2017-0013

28. Wolpert M, Harris R, Hodges S, et al. THRIVE Elaborated. London, UK: CAHMS Press; 2015.

29. Salloum A, Wang W, Robst J, et al. Stepped care versus standard traumafocused cognitive behavioral therapy for young children. J Child Psychol Psychiatry. 2016;57(5):614-622. doi:10.1111/jcpp.12471

30. Creswell C, Violato M, Fairbanks H, et al. Clinical outcomes and cost-effectiveness of brief guided parent-delivered cognitive behavioural therapy and solution-focused brief therapy for treatment of childhood anxiety disorders: a randomised controlled trial. Lancet Psychiatry. 2017;4(7):529-539. doi:10.1016/S2215-0366(17)30149-9

31. Yeguez CE, Page TF, Rey Y, Silverman WK, Pettit JW. A cost analysis of a stepped care treatment approach for anxiety disorders in youth. J Clin Child Adolesc Psychol. 2019;1-7. doi:10.1080/ 15374416.2018.1539913

32. World Health Organization. Mental Health Action Plan 2013-2020. Geneva: WHO; 2013. Available from: www.who.int/mental_health/ publications/action_plan/en. Accessed January 30, 2020.

33. NICE. Depression in children and young people: identification and management. Clinical guideline (NG134). National Institute for Health and Care Excellence; 2019. Available from: www.nice.org. uk/guidance/ng134. Accessed January 14, 2020.

34. Clark DM, Layard R, Smithies R, Richards DA, Suckling R, Wright B. Improving access to psychological therapy: initial evaluation of two UK demonstration sites. Behav Res Ther. 2009;47 (11):910-920. doi:10.1016/j.brat.2009.07.010 
35. Rapee RM, Lyneham HJ, Wuthrich V, et al. Comparison of stepped care delivery against a single, empirically validated cognitive-behavioral therapy program for youth with anxiety: a randomized clinical trial. J Am Acad Child Adolesc Psychiatry. 2017;56(10):841-848. doi:10. 1016/j.jaac.2017.08.001

36. NHS England. The NHS Long Term Plan. London, UK: NHS ENgland; 2019.

37. Fonagy P, Pugh K. CAMHS goes mainstream. Child Adolesc Ment Health. 2017;22(1):1-3. doi:10.1111/camh.12209

38. Montgomery EC, Kunik ME, Wilson N, Stanley MA, Weiss B. Can paraprofessionals deliver cognitive-behavioral therapy to treat anxiety and depressive symptoms? Bull Menninger Clin. 2010;74 (1):45-62. doi:10.1521/bumc.2010.74.1.45

39. Fonagy P, Pugh K, O'Herlihy A. The children and young people's improving access to psychological therapies (CYP IAPT) programme in England. Child Psychol Psychiatry. 2017;429-435. doi:10.1002/ 9781119170235.ch48

40. Sadler K, Vizard T, Ford T, et al. Mental Health of Children and Young People in England, 2017 Summary of Key Findings. London, UK: NHS Digital, Health and Social Information Centre; 2018. doi:10.2307/j.ctv39x8m4.19

41. Holmes EA, Ghaderi A, Harmer CJ, et al. The lancet psychiatry commission on psychological treatments research in tomorrow's science. Lancet Psychiatry. 2018;5(3):237-286. doi:10.1016/S22150366(17)30513-8

42. Fonagy P, Clark DM. Update on the improving access to psychological therapies programme in England: commentary on children and young people's improving access to psychological therapies. $B J$ Psych Bull. 2015;39(5):248-251. doi:10.1192/pb.bp.115.052282

43. Clark DM. Implementing NICE guidelines for the psychological treatment of depression and anxiety disorders: the IAPT experience. Int Rev Psychiatry. 2011;23(4):318-327. doi:10.3109/09540261.2011.606803

44. Barkham M, Margison F, Leach C, et al. Service profiling and outcomes benchmarking using the CORE-OM: toward practice-based evidence in the psychological therapies. $J$ Consult Clin Psychol. 2001;69(2):184. doi:10.1037/0022-006X.69.2.184

45. Thirlwall K, Cooper PJ, Karalus J, Voysey M, Willetts L, Creswell C. Treatment of child anxiety disorders via guided parent-delivered cognitive-behavioural therapy: randomised controlled trial. $\mathrm{Br}$ J Psychiatry. 2013;203(6):436-444. doi:10.1192/bjp.bp.113.126698

46. Sophie B, Roz S, Pim C, Fiona M, Emily B, Anup K. Practitioner review: unguided and guided self-help interventions for common mental health disorders in children and adolescents: a systematic review and meta-analysis. J Child Psychol Psychiatry. 2019. doi: $10.1111 /$ jcpp. 13010

47. NHS England. 2015 Adult IAPT Workforce Census Report. London: Health Education England; 2015.

48. Pass L, Brisco G, Reynolds S. Adapting brief Behavioural Activation (BA) for adolescent depression: a case example. Cogn Behav Ther. 2015;8. doi:10.1017/S1754470X15000446
49. O’Brien M, Daley D. Self-help parenting interventions for childhood behaviour disorders: a review of the evidence. Child Care Health Dev. 2011;37(5):623-637. doi:10.1111/j.1365-2214.2011.01231.x

50. Chorpita BF, Yim L, Moffitt C, Umemoto LA, Francis SE. Assessment of symptoms of DSM-IV anxiety and depression in children: a revised child anxiety and depression scale. Behav Res Ther. 2000;38(8):835-855. doi:10.1016/S0005-7967(99)00130-8

51. Goodman R, Ford T, Simmons H, Gatward R, Meltzer H. Using the Strengths and Difficulties Questionnaire (SDQ) to screen for child psychiatric disorders in a community sample. $\mathrm{Br} J$ Psychiatry. 2000;177(6):534-539. doi:10.1192/bjp.177.6.534

52. Law D, Jacob J. Goals and Goal Based Outcomes (GBOs). London: CAMHS Press; 2013.

53. Abrines-Jaume N, Midgley N, Hopkins K, et al. A qualitative analysis of implementing shared decision making in child and adolescent mental health services in the United Kingdom: stages and facilitators. Clin Child Psychol Psychiatry. 2016;21(1):19-31. doi:10.1177/ 1359104514547596

54. Cooper M, Law D. Working with Goals in Psychotherapy and Counselling. Oxford, UK: Oxford University Press; 2018.

55. Timimi S. Update on the improving access to psychological therapies programme in England: author's reply. BJ Psych Bull. 2015;39 (5):252-253. doi:10.1192/pb.bp.115.052399

56. Scott MJ. Improving Access to Psychological Therapies (IAPT) - the need for radical reform. $J$ Health Psychol. 2018;23(9):1136-1147. doi: $10.1177 / 1359105318755264$

57. Sachar A, Willis T, Basudev N. Mental health in diabetes: can't afford to address the service gaps or can't afford not to? $\mathrm{Br} J \mathrm{Gen}$ Pract. 2020;70(690):6-7. doi:10.3399/bjgp20X707261

58. Westwood S, Morison L, Allt J, Holmes N. Predictors of emotional exhaustion, disengagement and burnout among improving access to psychological therapies (IAPT) practitioners. J Ment Health. 2017;26 (2):172-179. doi:10.1080/09638237.2016.1276540

59. NICE. Depression in Children and Young People: 2019 Evidence Review. London, UK: National Institute for Health and Care Excellence; 2019.

60. NICE. Depression in Children and Young People: Identification and Management. Clinical Guideline (CG28). London, UK: National Institute of Clinical Excellence; 2005.

61. Clark DM, Canvin L, Green J, Layard R, Pilling S, Janecka M. Transparency about the outcomes of mental health services (IAPT approach): an analysis of public data. Lancet. 2018;391 (10121):679-686. doi:10.1016/S0140-6736(17)32133-5

62. Haukoos JS, Newgard CD. Advanced statistics: missing data in clinical research - part 1: an introduction and conceptual framework. Acad Emerg Med. 2007;14(7):662-668. doi:10.1111/j.15532712.2007.tb01855.x
Adolescent Health, Medicine and Therapeutics

\section{Publish your work in this journal}

Adolescent Health, Medicine and Therapeutics is an international, peer-reviewed, open access journal focusing on health, pathology, and treatment issues specific to the adolescent age group. All aspects of health maintenance, preventative measures and disease treatment interventions are addressed within the journal and practitioners from all disciplines are invited to submit their work as well as healthcare researchers and patient support groups. The manuscript management system is completely online and includes a very quick and fair peerreview system. Visit http://www.dovepress.com/testimonials.php to read real quotes from published authors. 